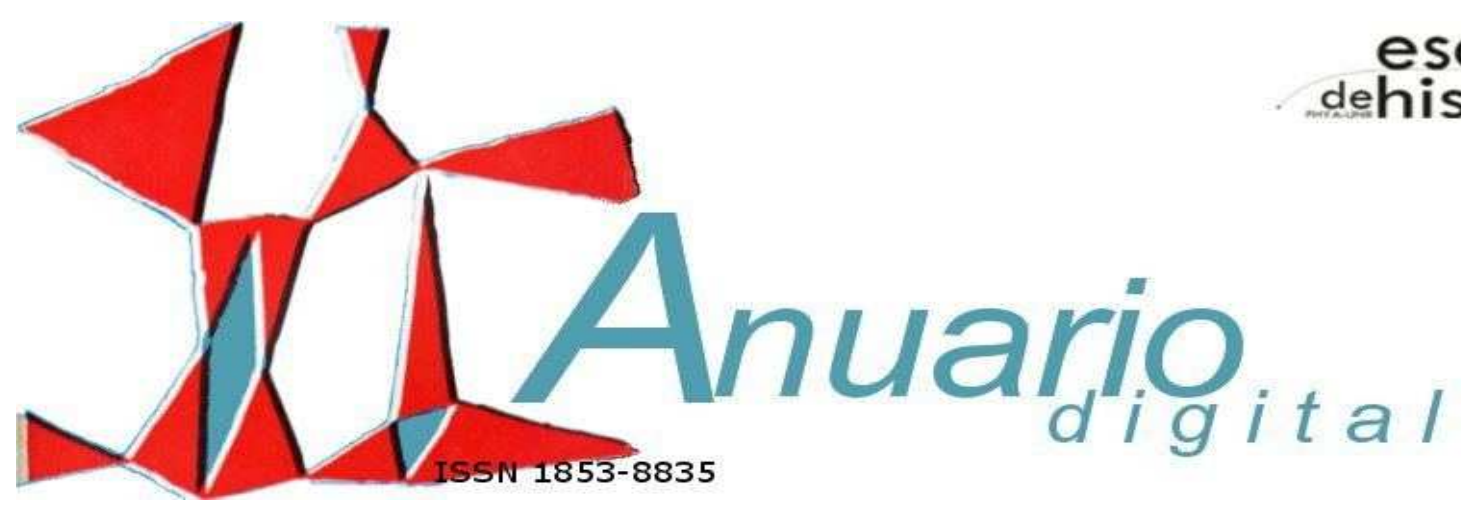

\title{
Las elecciones legislativas del 2001. Entre el "voto bronca" y el final del gobierno de la Alianza
}

The legislative election of 2001. Between the "angry vote" and the end of the Alianza's government

RESUMEN

El presente trabajo intentará dar cuenta de las elecciones legislativas nacionales del año 2001 en la Argentina, buscando señalar que las mismas representaron un suceso inédito en el país a partir de las diversas formas en que actuó la ciudadanía en ellas. Ya que en estas elecciones no sólo se produjo el extraordinario fenómeno conocido como "voto bronca" -el cual se impuso en algunos de los principales distritos-, sino que además fueron uno de los elementos fundamentales para sellar el destino del gobierno de Fernando De la Rúa, quien apenas dos meses después de ellas debió presentar su renuncia a la presidencia. Para hacer esto, repasaremos los resultados electorales a nivel nacional, deteniéndonos en algunos distritos puntuales donde el "voto bronca" actuó con mayor fuerza, tratando de vislumbrar los problemas de su ambigüedad, así como las consecuencias políticas que produjo.

Palabras clave: elecciones; 2001; democracia; voto bronca

\footnotetext{
* Maestrando en historia económica (UBA/Conicet).
} 
This paper will attempt to account for national legislative elections of 2001 in Argentina, trying to point out that they represented an unprecedented event in the country from the various ways in which citizens acted on them. Since in this election not only produced the extraordinary phenomenon known as "angry vote" -which won some major districts-, but also this was one of the key elements to seal the fate of the Fernando De la Rua's government, who just two months after they had submitted his resignation from the presidency. To do this, we will review the election results nationwide, stopping in some specific districts where "angry vote" acted as a major force, trying to envision the problems of ambiguity and the political consequences it produced.

Keywords: elections; 2001; democracy; angry vote

\section{Introducción Las elecciones argentinas en perspectiva histórica}

Los resultados generales de las elecciones del 14 de octubre de 2001 fueron uno de los fenómenos más novedosos y originales desde el retorno de la democracia. Su enorme lugar de trascendencia en el desarrollo de la crisis del año 2001 marcó un hito al acelerar la caída abrupta del gobierno de la Alianza (19992001) $)^{1}$. Las elecciones se produjeron en un contexto de crisis política y de recesión económica, en la cual el sistema de convertibilidad que había regido toda la década de 1990 estaba comenzando a provocar sus estragos finales. Así, desde el comienzo de su mandato, el gobierno de la Alianza había apostado todo su capital político a salvar la paridad cambiaria decidiéndose por realizar ajustes permanentes con el fin de equilibrar las cuentas fiscales para evitar una devaluación. Empero, sin muchos resultados al respecto, terminó por acudir en marzo de 2001 a Domingo Cavallo como último recurso para salvar la situación. Sin embargo, y no obstante los esfuerzos de Cavallo, tampoco se pudo evitar que se realizaran corridas bancarias, fuga de capitales o que subiera el índice riesgo país. Así, a poco del arribo del nuevo ministro el gobierno, en julio, aplicó la ley de Déficit Cero, que implicó un recorte del 13\% de las jubilaciones y de todos los sueldos

\footnotetext{
${ }^{1}$ La Alianza fue una coalición política conformada por la Unión Cívica Radical (UCR) y el Frente País Solidario (Frepaso).
}

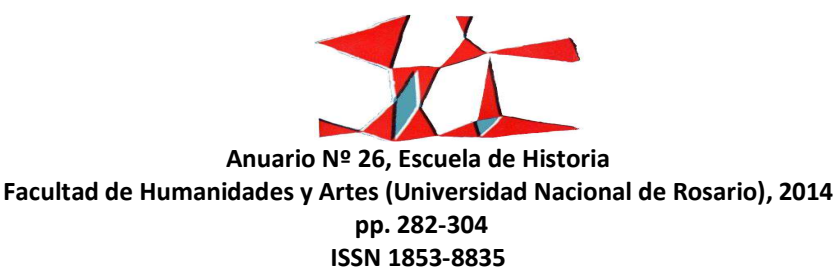


estatales, la cual igualmente no revirtió las tendencias recesivas, sino que las agudizóz. Por lo que la situación económica se deterioró aún más bajo un clima desesperante, creando las condiciones que permitían prever un disgusto generalizado de la ciudadanía a plasmarse en dichas elecciones de octubre ${ }^{3}$.

Con todo, y pesar de estos datos y de lo cruenta que pudiera ser la crisis económica, los resultados de esas elecciones no dejaron de ser sorprendentes, como tampoco lo fueron las marcas que implicaron: la suma de los dos principales partidos políticos llegó a representar apenas el 30\% del padrón nacional, modificando las pautas del proceso en juego, al quitarle abrumadoramente el respaldo al gobierno. Ya otros actos eleccionarios de la historia argentina habían actuado de forma similar. Por ejemplo, dentro del siglo XX, las elecciones de 1931 en la provincia de Buenos Aires fueron las que dejaron al gobierno militar de Félix Uriburu herido de muerte tras imponerse el derrocado radicalismo nuevamente allí. Lo mismo que ocurrió con Frondizi en 1962 con respecto al triunfo peronista. Sin dejar de lado aquellas que también priorizaron juegos alternativos de significación política, cuando con la proscripción peronista los votos en blanco tuvieron un rol primordial para debilitar a diversos gobiernos (la Revolución Libertadora -1957-, Frondizi-1960- e Illia $-1963-)$.

En efecto, siempre un suceso electoral abre espacios de fuerte connotación y significación política. Por ejemplo, la realización de elecciones puede ser circunscripta a un rol "funcional-institucional" (votar para elegir autoridades) como también "cíclico-ritual" (repetición y sedimentación de prácticas sociales), aunque apelar a él pueda además agregar otras instancias de significación. Es decir, debemos tener en cuenta que la existencia (o no) de un acto eleccionario en las sociedades contemporáneas representa también el espacio de validación mítica de su forma política de funcionamiento y a la cual apelan como su fuente de legitimidad en la democracia electiva. En este sentido, cuestionar sus mecanismos formales de operatoria y la distribución de sus espacios de poder implica también llevar los cuestionamientos al corazón mismo del régimen: los fundamentos del orden vigente pueden verse amenazados si existen importantes controversias respecto a sus resultados. Bajo el vertiginoso desarrollo del proceso histórico que estaba ocurriendo en la Argentina durante el 2001, todo lo sólido podía desvanecerse en el aire. En este sentido, que una gran porción del

\footnotetext{
${ }^{2}$ Para un análisis de la dinámica económica del 2001 ver Zícari, Julián. “El réquiem del uno a uno. Tres corridas bancarias y la instauración del corralito en el final de la convertibilidad". Realidad Económica, N² 281, 1 de enero al 15 de febrero de 2014.

${ }^{3}$ Para un estudio del clima político preelectoral ver Herrero, Fabián; “"¿Pasividad desesperada o protesta astuta? ¿Desperdicio o mensaje a la clase política?» Intervenciones sobre cómo pensar el «voto bronca» en el momento previo a las elecciones nacionales de 2001", en Revista Estudios, Córdoba, N²6, 2011.
}

285

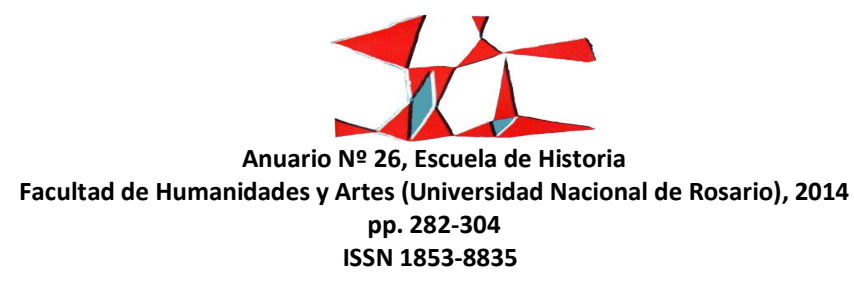


electorado se hubiera expresado a través de claros signos de malestar podía transformar al acto eleccionario de octubre en una señal anómica para el "normal" funcionamiento de las reglas de juego vigentes, volviendo al futuro un campo potencialmente crispado que podía emerger revestido de múltiples formas. Así, la posibilidad de objetar la raíz misma de la estructura institucional, a través de un resultado electoral desfavorable, podía transformarse en un ataque (virtualmente mortal) para las principales fuentes de legitimidad gubernamental. Algo que no sólo operó en el final del gobierno de la Alianza y en los estallidos sociales que lo precedieron, sino también en el famoso "que se vayan todos" posterior, como en la emergencia de las asambleas barriales y en el intento de recomponer el sistema de partidos más allá del 2001. Es por eso no deja de resultar indispensable comprender cómo operó el grueso de la ciudadanía en estas elecciones.

\section{Distintas formas de aproximarse al "voto bronca": resultados, tendencias, significados}

Los cuestionamientos y las muestras de disconformidad llevados a cabo a partir de las elecciones de octubre se expresaron en un nivel masivo, lo cual nos obliga a ser cuidadosos sobre el sentido que esto tiene. No creemos que pueda predominar como principal lectura la "apoliticidad" de la ciudadanía en general, como se leyó en algunos medios de prensa en esa coyuntura ${ }^{4}$, que sostenían que la apatía extendida y el desinterés por el desarrollo del proceso habrían sido los principales móviles de los electores. Hacerlo sería confundir en una forma muy pobre "política" con "elecciones". Los sucesos electorales de octubre se encuentran lejos de expresarse bajo una forma de indiferencia vacía y carente de sentido. Al contrario, la novedad y las rupturas introducidas durante las jornadas parecen querer plagar de significación y buscar redefinir las maneras de participación política que de abstenerse de omitir algún tipo de opinión al respecto. Los cambios con respecto a los modos tradicionales de intervención política más que un silencio indican una nueva forma de voz. A su vez, también sostenemos que deben dejarse de lado las explicaciones del descontento ciudadano por el simple cansancio o repudio de las "prácticas corruptas de los políticos" como también circuló durante ésas jornadas. Varios dirigentes políticos asociados a una imagen espuria y poco transparente (como Menem) gozaban de un importante nivel de aceptación y en la coyuntura de octubre lograron imponerse en sus

${ }^{4}$ Por ejemplo, ver algunas notas del diario Ámbito Financiero (15/10/2001).

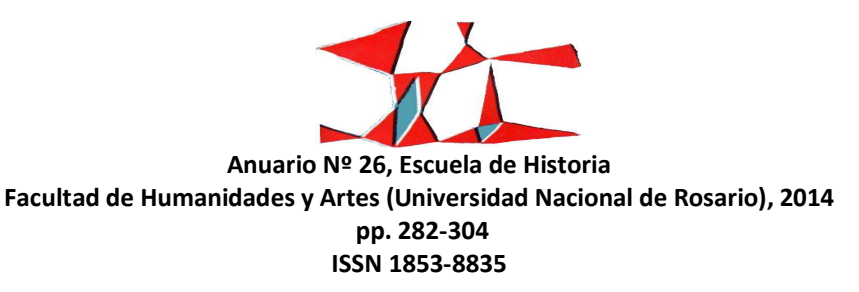


distritos. En este sentido, realizar una desagregación de los datos nos permitirá dar luz al fenómeno de manera más robusta.

Cuadro $\mathrm{N}^{\circ} 1$ : Valores absolutos y relativos de los votos positivos, en blanco, anulados, ausentismo, total de participantes y padrón de habilitados en elecciones nacionales (1983-2001)

\begin{tabular}{|c|c|c|c|c|c|c|c|c|c|c|c|}
\hline Año & 1983 & 1985 & 1987 & 1989 & 1991 & 1993 & 1995 & 1997 & 1999 & $\begin{array}{l}\text { Prom. } \\
83-99\end{array}$ & 2001 \\
\hline \multirow{3}{*}{$\begin{array}{c}\text { Votos } \\
\text { positivos }\end{array}$} & 14.869 .372 & 15.324 .510 & 16.037 .652 & 16.694 .570 & 15.634 .173 & 16.361 .025 & 17.174.749 & 17.251.484 & 18.953 .456 & - & 14.420 .387 \\
\hline & $97,42 \%$ & $98,07 \%$ & $97,54 \%$ & $97,82 \%$ & $94,20 \%$ & $94,89 \%$ & $94,53 \%$ & $93,39 \%$ & $95,49 \%$ & $95,93 \%$ & $76,70 \%$ \\
\hline & $82,93 \%$ & $82,15 \%$ & $82,44 \%$ & $83,33 \%$ & $75,29 \%$ & $76,23 \%$ & $77,44 \%$ & $74,36 \%$ & $78,61 \%$ & $79,20 \%$ & $57,89 \%$ \\
\hline \multirow{3}{*}{$\begin{array}{c}\text { Votos } \\
\text { en blanco }\end{array}$} & 384.087 & 205.406 & 326.959 & 264.732 & 834.527 & 700562 & 870.382 & 958.673 & 708.793 & - & 1.877 .724 \\
\hline & $2,52 \%$ & $1,31 \%$ & $1,99 \%$ & $1,55 \%$ & $5,03 \%$ & $4,06 \%$ & $4,79 \%$ & $5,19 \%$ & $3,57 \%$ & $3,33 \%$ & $9,99 \%$ \\
\hline & $2,14 \%$ & $1,10 \%$ & $1,68 \%$ & $1,32 \%$ & $4,02 \%$ & $3,26 \%$ & $3,92 \%$ & $4,13 \%$ & $2,94 \%$ & $2,72 \%$ & $7,54 \%$ \\
\hline \multirow{3}{*}{$\begin{array}{c}\text { Votos } \\
\text { anulados }\end{array}$} & 10.286 & 96.353 & 77.247 & 107.618 & 127.252 & 180554 & 123.971 & 262.216 & 186.738 & - & 2.502 .869 \\
\hline & $0,07 \%$ & $0,62 \%$ & $0,47 \%$ & $0,63 \%$ & $0,77 \%$ & $1,05 \%$ & $0,68 \%$ & $1,42 \%$ & $0,94 \%$ & $0,74 \%$ & $13,31 \%$ \\
\hline & $0,06 \%$ & $0,52 \%$ & $0,40 \%$ & $0,54 \%$ & $0,61 \%$ & $0,84 \%$ & $0,56 \%$ & $1,13 \%$ & $0,77 \%$ & $0,60 \%$ & $10,05 \%$ \\
\hline \multirow{3}{*}{ Ausentes } & 2.666 .206 & 3.027 .218 & 3.011 .149 & 2.967 .333 & 4.168 .060 & 4.221 .620 & 4.009 .054 & 4.727 .441 & 4.262 .283 & - & 6.106 .859 \\
\hline & $17,47 \%$ & $19,37 \%$ & $18,31 \%$ & $17,39 \%$ & $25,11 \%$ & $24,48 \%$ & $22,07 \%$ & $25,59 \%$ & $21,47 \%$ & $21,25 \%$ & $32,48 \%$ \\
\hline & $14,87 \%$ & $16,23 \%$ & $15,48 \%$ & $14,81 \%$ & $20,07 \%$ & $19,67 \%$ & $18,08 \%$ & $20,38 \%$ & $17,68 \%$ & $17,47 \%$ & $24,52 \%$ \\
\hline Total & 15.263 .745 & 15.626 .269 & 16.441 .858 & 17.066 .920 & 16.595 .952 & 17.242 .141 & 18.169 .101 & 18.472 .373 & 19.848 .987 & - & 18.800 .980 \\
\hline Particip. & $85,13 \%$ & $83,77 \%$ & $84,52 \%$ & $85,19 \%$ & $79,93 \%$ & $80,33 \%$ & $81,92 \%$ & $79,62 \%$ & $82,32 \%$ & $82,53 \%$ & $75,48 \%$ \\
\hline $\begin{array}{c}\text { Total } \\
\text { Padrón }\end{array}$ & 17.929.951 & 18.653 .487 & 19.453 .007 & 20.034 .252 & 20.764.012 & 21.463.761 & 22.178.154 & 23.199.814 & 24.111.270 & - & 24.907 .838 \\
\hline
\end{tabular}

Nota: El primer reglón de cada categoría expresa el número absoluto de votos, el segundo señala el lugar relativo con relación a la participación activa total (concurrencia), mientras que el tercer reglón lo hace con respecto al total de votantes habilitados (Padrón electoral). Fuente: Elaboración propia en base a datos Ministerio del Interior ${ }^{5}$.

Como vemos, el Cuadro $N^{\circ} 1$ nos permite tener una visión global de lo ocurrido en octubre de 2001 pudiendo establecer comparaciones con las principales tendencias históricas desde el retorno de la democracia en 1983. De esta manera, podemos sacar dos tipos de conclusiones de relevancia para nuestro análisis. La primera, se refiere a notar la creciente tendencia a la abstención electoral desde el año 1983 al 2001. La segunda, busca señalar la propensión zigzagueante de ésta, puesto que no todos los años decrece el número de participantes en los comicios electorales. La concurrencia tiende a ser mayor cuando se trata de años de elección presidencial y a ser más baja cuando se trata sólo de una elección legislativa. Por lo cual, al comparar los promedios de ausencia electoral entre períodos, notamos que en el comprendido entre 1983-

\footnotetext{
${ }^{5}$ Aclaración metodológica: en los casos en que se realizaron más de un tipo de elección en una misma fecha (por ejemplo elección en forma simultánea de presidente, diputados, senadores, concejales, gobernadores, etc.) se procedió a tomar el promedio de todas ellas, logrando así obtener un solo valor testigo por cada año electoral. Esta metodología será la que regirá -salvo indicación contraria- todos los valores expuestos en adelante.
}

287

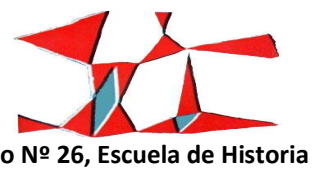

Facultad de Humanidades y Artes (Universidad Nacional de Rosario), 2014

pp. 282-304

ISSN 1853-8835 
1999 fue de 17,48\% mientras que lo ocurrido para el 2001 señala un número sensiblemente mayor, 24,52\%, existiendo una diferencia de 7 puntos porcentuales entre la media histórica y el año 2001. Sin embargo, si comparamos esta última fecha con el nivel de inasistencias de la elección legislativa inmediatamente anterior (20,38\% en 1997) comprobamos que el crecimiento de ausencias no es tan grande como el que a primera vista podríamos haber pensado, tan sólo existe un $4 \%$ del padrón electoral de desvío. A su vez, si especulamos con realizar una proyección de la tendencia existente desde 1983, de creciente nivel de ausencias, podríamos comprobar que no existe en este caso un quiebre histórico de gran relevancia. En este sentido, la mayoría de la población, lejos de manifestar indiferencia o apatía con respecto a años anteriores, continuó actuando con niveles similares de concurrencia, más allá de que un nivel de ausentismo cercano al $25 \%$ no es un dato menor dentro de un sistema electoral donde la participación es obligatoria. A su vez, también debe tenerse en cuenta que si la tasa de participación electoral argentina se considera baja $(82,53 \%$ como media histórica y 75,48\% en 2001) ésta es superior a lo ocurrido en casi todo el continente americano, siendo una de las tasas más altas de concurrencia, incluso también en comparación con lo que ocurre en varios países europeos.

Con respecto a la desviación provincial del promedio de la nación no hubo una clara dispersión a lo largo de todo el territorio nacional. De los 24 distritos electorales, 12 estuvieron por encima de la media nacional, ubicándose los restantes 12 por debajo. Aunque, en los lugares con menores niveles de desarrollo y mayor pobreza, la concurrencia fue más exigua. Santiago del Estero, Corrientes, Tucumán, Salta y Formosa $(33,15 \%, 31,10 \%, 31,01 \% 29,43 \%$ y $29,39 \%$ respectivamente) fueron las provincias con mayores niveles de ausentismo con respecto a lo ocurrido en el resto del país. Mientras que La Pampa $(19,87 \%)$ y Entre Ríos $(21,12 \%)$ registraron las tasas más bajas de ausencias.

Ahora bien, si podemos descartar -o por lo menos minimizar- lo ocurrido con respecto al nivel de ausencia, sin dejar de contemplarlo como otra forma de emisión de opinión, debemos considerar que gran parte del significado de las elecciones 2001 no apuntó a desconocer o a repudiar el sistema de juego de la democracia electiva. Quienes estuvieron en condiciones de votar no señalaron un nivel sustancialmente más elevado de desinterés en el escrutinio con respecto a otros años, ya que la apuesta a la participación siguió

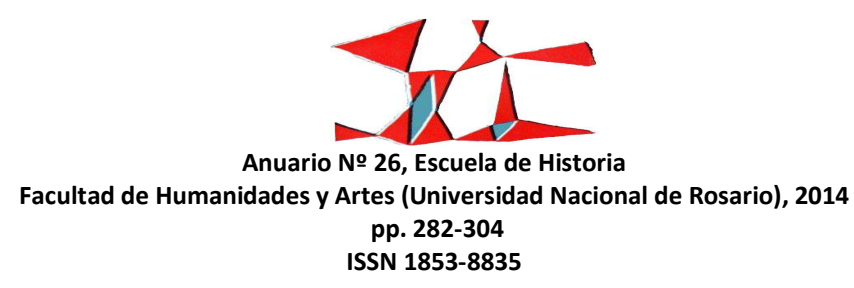


siendo la opción más elevada 6 . Así, si bien existió disconformidad, creemos que tuvo otros destinatarios y formas. Veámoslo con detenimiento.

Cuadro 2: Valores absolutos y relativos de los votos positivos, en blanco, anulados, ausentismo, total de participantes y padrón de habilitados desagregados por distrito electoral para las elecciones de 2001

\begin{tabular}{|c|c|c|c|c|c|c|c|}
\hline \multirow{2}{*}{ Distrito } & Voto Positivo & Voto en Blanco & Voto Nulo & Voto "Bronca" & Ausentes & Participación Efectiva & Total Habilitados \\
\hline & 1 & 2 & 3 & $2+3=4$ & 5 & $1+4=6$ & $5+6=7$ \\
\hline $\begin{array}{l}\text { Total } \\
\text { Nación }\end{array}$ & $\begin{array}{c}\mathbf{1 4 . 4 2 0 . 3 8 7} \\
76,70 \% \\
57,89 \%\end{array}$ & $\begin{array}{c}1.877 .724 \\
9,99 \% \\
7,54 \%\end{array}$ & $\begin{array}{c}\mathbf{2 . 5 0 2 . 8 6 9} \\
13,31 \% \\
10,05 \%\end{array}$ & $\begin{array}{c}\mathbf{4 . 3 8 0 . 5 9 3} \\
23,30 \% \\
17,59 \%\end{array}$ & $\begin{array}{c}\mathbf{6 . 1 0 6 . 8 5 9} \\
32,48 \% \\
24,52 \%\end{array}$ & $\begin{array}{c}\mathbf{1 8 . 8 0 0 . 9 8 0} \\
100,00 \% \\
75,48 \%\end{array}$ & $\begin{array}{c}24.907 .838 \\
- \\
100,00 \%\end{array}$ \\
\hline $\begin{array}{l}\text { Capital } \\
\text { Federal }\end{array}$ & $\begin{array}{c}\mathbf{1 . 3 4 4 . 0 2 9} \\
71,19 \% \\
51,98 \% \\
\end{array}$ & $\begin{array}{c}\mathbf{8 2 . 0 5 5} \\
4,35 \% \\
3,17 \% \\
\end{array}$ & $\begin{array}{c}461.762 \\
24,46 \% \\
17,86 \% \\
\end{array}$ & $\begin{array}{l}\mathbf{5 4 3 . 8 1 7} \\
28,81 \% \\
21,03 \% \\
\end{array}$ & $\begin{array}{l}\mathbf{6 9 7 . 6 7 9} \\
36,96 \% \\
26,98 \% \\
\end{array}$ & $\begin{array}{c}\mathbf{1 . 8 8 7 . 8 4 6} \\
100,00 \% \\
73,02 \% \\
\end{array}$ & $\begin{array}{c}\mathbf{2 . 5 8 5 . 5 2 5} \\
- \\
100,00 \% \\
\end{array}$ \\
\hline $\begin{array}{l}\text { Provincia } \\
\text { de Bs. As. }\end{array}$ & $\begin{array}{c}\mathbf{5 . 4 0 7 . 9 7 7} \\
75,58 \% \\
58,24 \% \\
\end{array}$ & $\begin{array}{c}736.247 \\
10,29 \% \\
7,93 \% \\
\end{array}$ & $\begin{array}{c}\mathbf{1 . 0 1 1 . 5 3 8} \\
14,14 \% \\
10,89 \% \\
\end{array}$ & $\begin{array}{c}1.747 .785 \\
24,42 \% \\
18,82 \% \\
\end{array}$ & $\begin{array}{c}\mathbf{2 . 1 2 9 . 1 5 4} \\
29,75 \% \\
22,93 \% \\
\end{array}$ & $\begin{array}{c}7.155 .761 \\
100,00 \% \\
77,07 \% \\
\end{array}$ & $\begin{array}{c}9.284 .915 \\
- \\
100,00 \% \\
\end{array}$ \\
\hline Córdoba & $\begin{array}{c}\mathbf{1 . 3 0 2 . 4 5 9} \\
78,57 \% \\
59,76 \%\end{array}$ & $\begin{array}{c}\mathbf{1 8 6 . 7 3 6} \\
11,26 \% \\
8,57 \% \\
\end{array}$ & $\begin{array}{c}\mathbf{1 6 8 . 5 2 8} \\
10,17 \% \\
7,73 \% \\
\end{array}$ & \begin{tabular}{|l|}
355.264 \\
$21,43 \%$ \\
$16,30 \%$ \\
\end{tabular} & $\begin{array}{l}\mathbf{5 2 1 . 7 2 8} \\
31,47 \% \\
23,94 \% \\
\end{array}$ & $\begin{array}{c}\mathbf{1 . 6 5 7 . 7 2 2} \\
100,00 \% \\
76,06 \%\end{array}$ & $\begin{array}{c}\mathbf{2 . 1 7 9 . 4 5 0} \\
- \\
100,00 \% \\
\end{array}$ \\
\hline Santa Fe & $\begin{array}{r}\mathbf{9 8 7 . 4 0 9} \\
57,92 \% \\
44,90 \% \\
\end{array}$ & $\begin{array}{l}\mathbf{5 2 1 . 3 1 6} \\
30,58 \% \\
23,70 \% \\
\end{array}$ & \begin{tabular}{|c|}
$\mathbf{1 9 6 . 0 2 4}$ \\
$11,50 \%$ \\
$8,91 \%$ \\
\end{tabular} & $\begin{array}{l}\mathbf{7 1 7 . 3 4 0} \\
42,08 \% \\
32,62 \% \\
\end{array}$ & $\begin{array}{l}494.468 \\
29,01 \% \\
22,48 \% \\
\end{array}$ & $\begin{array}{c}1.704 .748 \\
100,00 \% \\
77,52 \% \\
\end{array}$ & $\begin{array}{c}2.199 .216 \\
- \\
100,00 \% \\
\end{array}$ \\
\hline Mendoza & $\begin{array}{l}654.495 \\
80,26 \% \\
61,93 \% \\
\end{array}$ & $\begin{array}{l}\mathbf{6 1 . 5 2 4} \\
7,54 \% \\
5,82 \% \\
\end{array}$ & \begin{tabular}{|l|}
$\mathbf{9 9 . 4 3 6}$ \\
$12,19 \%$ \\
$9,41 \%$ \\
\end{tabular} & $\begin{array}{l}\mathbf{1 6 0 . 9 6 0} \\
19,74 \% \\
15,23 \% \\
\end{array}$ & $\begin{array}{l}\mathbf{2 4 1 . 3 5 4} \\
29,60 \% \\
22,84 \% \\
\end{array}$ & \begin{tabular}{c|}
$\mathbf{8 1 5 . 4 5 4}$ \\
$100,00 \%$ \\
$77,16 \%$ \\
\end{tabular} & $\begin{array}{c}1.056 .808 \\
- \\
100,00 \% \\
\end{array}$ \\
\hline Catamarca & $\begin{array}{l}149824 \\
92,15 \% \\
71,61 \% \\
\end{array}$ & $\begin{array}{c}7950 \\
4,89 \% \\
3,80 \% \\
\end{array}$ & $\begin{array}{c}\mathbf{4 8 1 7} \\
2,96 \% \\
2,30 \% \\
\end{array}$ & $\begin{array}{l}12.767 \\
7,85 \% \\
6,10 \% \\
\end{array}$ & $\begin{array}{l}\mathbf{4 6 . 6 2 1} \\
28,67 \% \\
22,28 \% \\
\end{array}$ & \begin{tabular}{c|}
$\mathbf{1 6 2 . 5 9 1}$ \\
$100,00 \%$ \\
$\mathbf{7 7 , 7 2 \%}$ \\
\end{tabular} & $\begin{array}{c}209.212 \\
- \\
100,00 \% \\
\end{array}$ \\
\hline Corrientes & $\begin{array}{l}397.472 \\
97,35 \% \\
67,07 \% \\
\end{array}$ & $\begin{array}{c}797 \\
0,20 \% \\
0,13 \% \\
\end{array}$ & $\begin{array}{l}10.035 \\
2,46 \% \\
1,69 \% \\
\end{array}$ & $\begin{array}{l}10.832 \\
2,65 \% \\
1,83 \% \\
\end{array}$ & $\begin{array}{l}\mathbf{1 8 4 . 3 1 8} \\
45,14 \% \\
31,10 \% \\
\end{array}$ & \begin{tabular}{c|}
$\mathbf{4 0 8 . 3 0 3}$ \\
$100,00 \%$ \\
$68,90 \%$ \\
\end{tabular} & $\begin{array}{c}\mathbf{5 9 2 . 6 2 1} \\
- \\
100,00 \% \\
\end{array}$ \\
\hline Chaco & $\begin{array}{l}\mathbf{4 3 5 . 9 5 0} \\
92,83 \% \\
69,12 \% \\
\end{array}$ & $\begin{array}{l}14.709 \\
3,13 \% \\
2,33 \% \\
\end{array}$ & $\begin{array}{l}18.939 \\
4,03 \% \\
3,00 \% \\
\end{array}$ & \begin{tabular}{|l|}
$\mathbf{3 3 . 6 4 8}$ \\
$7,17 \%$ \\
$5,34 \%$ \\
\end{tabular} & $\begin{array}{l}\mathbf{1 6 1 . 0 8 3} \\
34,30 \% \\
25,54 \% \\
\end{array}$ & $\begin{array}{c}\mathbf{4 6 9 . 5 9 8} \\
100,00 \% \\
74,46 \% \\
\end{array}$ & $\begin{array}{c}\mathbf{6 3 0 . 6 8 1} \\
- \\
100,00 \% \\
\end{array}$ \\
\hline Chubut & $\begin{array}{l}149287 \\
74,87 \% \\
56,08 \% \\
\end{array}$ & $\begin{array}{c}\mathbf{1 2 9 8 3 , 5} \\
6,51 \% \\
4,88 \% \\
\end{array}$ & $\begin{array}{l}\mathbf{3 7 1 3 3 , 5} \\
\mathbf{1 8 , 6 2 \%} \\
13,95 \% \\
\end{array}$ & $\begin{array}{l}\mathbf{5 0 . 1 1 7} \\
25,13 \% \\
18,83 \% \\
\end{array}$ & $\begin{array}{l}\mathbf{6 6 . 8 2 0} \\
33,51 \% \\
25,10 \% \\
\end{array}$ & $\begin{array}{c}199.404 \\
100,00 \% \\
74,90 \% \\
\end{array}$ & $\begin{array}{l}\mathbf{2 6 6 . 2 2 4} \\
133,51 \% \\
100,00 \% \\
\end{array}$ \\
\hline Entre Ríos & $\begin{array}{l}495.046 \\
78,20 \% \\
61,68 \%\end{array}$ & $\begin{array}{l}\mathbf{2 4 . 5 6 9} \\
3,88 \% \\
3,06 \%\end{array}$ & $\begin{array}{l}113.475 \\
17,92 \% \\
14,14 \% \\
\end{array}$ & $\begin{array}{l}\mathbf{1 3 8 . 0 4 4} \\
21,80 \% \\
17,20 \% \\
\end{array}$ & $\begin{array}{l}\mathbf{1 6 9 . 5 0 8} \\
26,77 \% \\
21,12 \% \\
\end{array}$ & $\begin{array}{c}\mathbf{6 3 3 . 0 9 0} \\
100,00 \% \\
78,88 \%\end{array}$ & $\begin{array}{c}\mathbf{8 0 2 . 5 9 8} \\
- \\
100,00 \%\end{array}$ \\
\hline Formosa & $\begin{array}{l}\mathbf{1 8 7 . 4 9 7} \\
91,80 \% \\
64,82 \% \\
\end{array}$ & $\begin{array}{l}\mathbf{5 . 2 2 3} \\
2,56 \% \\
1,81 \% \\
\end{array}$ & $\begin{array}{l}\mathbf{1 1 . 5 2 6} \\
5,64 \% \\
3,98 \% \\
\end{array}$ & $\begin{array}{c}\mathbf{1 6 . 7 4 9} \\
8,20 \% \\
5,79 \% \\
\end{array}$ & \begin{tabular}{|l|}
85.006 \\
$41,62 \%$ \\
$29,39 \%$ \\
\end{tabular} & \begin{tabular}{c|}
$\mathbf{2 0 4 . 2 4 5}$ \\
$100,00 \%$ \\
$70,61 \%$ \\
\end{tabular} & $\begin{array}{c}\mathbf{2 8 9 . 2 5 1} \\
- \\
100,00 \% \\
\end{array}$ \\
\hline
\end{tabular}

\begin{tabular}{|c|c|c|c|c|c|c|c|}
\hline Jujuy & 202.474 & 30.689 & 31.398 & 62.087 & 95.149 & 264.561 & 359.710 \\
\hline
\end{tabular}

${ }^{6}$ Igualmente esto, también se ha señalado: “Los que se inclinaron por esta opción [la abstención para expresar el descontento] no creyeron en la utilidad -o por lo menos, en la apuesta- de esta elección. Por su carácter menos inédito, por ser una expresión indirecta y más ambigua, la abstención puede parecer la modalidad menos fuerte de la protesta. Sin embargo, esa interpretación es válida sólo en el corto plazo, porque si bien la abstención expresa menos cólera, lo cierto es que expresa también una resignación con respecto a la democracia y su capacidad para resolver los problemas". Basset, Yann. "Abstención y voto negativo. De la interpretación sociológica a la lógica política" en Cheresky, Isidoro y Blanquer, Jean (comp.) De la ilusión reformista al descontento ciudadano. Las elecciones en la Argentina. 1999-2001. Homo Sapiens Ediciones, Rosario, 2001, p. 67.

289

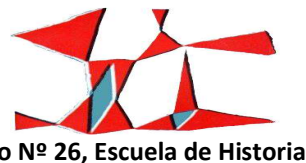

Facultad de Humanidades y Artes (Universidad Nacional de Rosario), 2014

pp. 282-304

ISSN 1853-8835 


\begin{tabular}{|c|c|c|c|c|c|c|c|}
\hline & $\begin{array}{r}76,53 \% \\
56,29 \% \\
\end{array}$ & $\begin{array}{c}11,60 \% \\
8,53 \% \\
\end{array}$ & $\begin{array}{c}11,87 \% \\
8,73 \% \\
\end{array}$ & $\begin{array}{l}23,47 \% \\
17,26 \% \\
\end{array}$ & $\begin{array}{l}35,96 \% \\
26,45 \% \\
\end{array}$ & $\begin{array}{c}100,00 \% \\
73,55 \% \\
\end{array}$ & $\begin{array}{c}- \\
100,00 \%\end{array}$ \\
\hline La Pampa & $\begin{array}{c}144.833 \\
83,75 \% \\
67,11 \%\end{array}$ & $\begin{array}{l}7.357 \\
4,25 \% \\
3,41 \% \\
\end{array}$ & $\begin{array}{c}\mathbf{2 0 . 7 5 6} \\
12,00 \% \\
9,62 \%\end{array}$ & $\begin{array}{l}\mathbf{2 8 . 1 1 2} \\
16,25 \% \\
13,03 \%\end{array}$ & $\begin{array}{l}42.885 \\
24,80 \% \\
19,87 \%\end{array}$ & $\begin{array}{c}\mathbf{1 7 2 . 9 4 5} \\
100,00 \% \\
80,13 \%\end{array}$ & $\begin{array}{c}215.830 \\
- \\
100,00 \%\end{array}$ \\
\hline La Rioja & $\begin{array}{c}123.654 \\
84,45 \% \\
67,33 \%\end{array}$ & $\begin{array}{c}16.603 \\
11,34 \% \\
9,04 \%\end{array}$ & $\begin{array}{c}6.165 \\
4,21 \% \\
3,36 \%\end{array}$ & $\begin{array}{l}\mathbf{2 2 . 7 6 7} \\
15,55 \% \\
12,40 \%\end{array}$ & $\begin{array}{l}37.222 \\
25,42 \% \\
20,27 \%\end{array}$ & $\begin{array}{c}146.421 \\
100,00 \% \\
79,73 \%\end{array}$ & $\begin{array}{c}183.643 \\
- \\
100,00 \%\end{array}$ \\
\hline Misiones & $\begin{array}{c}369.938 \\
87,74 \% \\
64,43 \% \\
\end{array}$ & $\begin{array}{c}\mathbf{2 6 . 0 8 0} \\
6,19 \% \\
4,54 \% \\
\end{array}$ & $\begin{array}{c}\mathbf{2 5 . 5 9 7} \\
6,07 \% \\
4,46 \% \\
\end{array}$ & $\begin{array}{c}\mathbf{5 1 . 6 7 6} \\
12,26 \% \\
9,00 \% \\
\end{array}$ & $\begin{array}{c}\mathbf{1 5 2 . 5 2 4} \\
36,18 \% \\
26,57 \% \\
\end{array}$ & $\begin{array}{c}\mathbf{4 2 1 . 6 1 4} \\
100,00 \% \\
73,43 \% \\
\end{array}$ & $\begin{array}{c}\mathbf{5 7 4 . 1 3 8} \\
- \\
100,00 \% \\
\end{array}$ \\
\hline Neuquén & $\begin{array}{c}174.442 \\
74,73 \% \\
58,05 \% \\
\end{array}$ & $\begin{array}{c}\mathbf{2 2 . 5 2 4} \\
9,65 \% \\
7,50 \% \\
\end{array}$ & $\begin{array}{l}\mathbf{3 6 . 4 7 7} \\
15,63 \% \\
12,14 \% \\
\end{array}$ & $\begin{array}{l}59.002 \\
25,27 \% \\
19,63 \% \\
\end{array}$ & $\begin{array}{l}67.070 \\
28,73 \% \\
22,32 \% \\
\end{array}$ & $\begin{array}{c}\mathbf{2 3 3 . 4 4 4} \\
100,00 \% \\
77,68 \% \\
\end{array}$ & $\begin{array}{c}300.514 \\
- \\
100,00 \% \\
\end{array}$ \\
\hline Río Negro & $\begin{array}{c}\mathbf{1 8 1 . 8 1 1} \\
71,53 \% \\
53,30 \% \\
\end{array}$ & $\begin{array}{c}10.062 \\
3,96 \% \\
2,95 \%\end{array}$ & $\begin{array}{l}62.293 \\
24,51 \% \\
18,26 \%\end{array}$ & $\begin{array}{l}72.354 \\
28,47 \% \\
21,21 \%\end{array}$ & $\begin{array}{l}\mathbf{8 6 . 9 3 0} \\
34,20 \% \\
25,49 \%\end{array}$ & $\begin{array}{c}\mathbf{2 5 4 . 1 6 5} \\
100,00 \% \\
74,51 \% \\
\end{array}$ & $\begin{array}{c}341.095 \\
- \\
100,00 \%\end{array}$ \\
\hline Salta & $\begin{array}{c}380.602 \\
82,60 \% \\
58,29 \%\end{array}$ & $\begin{array}{c}\mathbf{4 8 . 8 2 4} \\
10,60 \% \\
7,48 \%\end{array}$ & $\begin{array}{c}31.325 \\
6,80 \% \\
4,80 \%\end{array}$ & $\begin{array}{l}\mathbf{8 0 . 1 4 9} \\
17,40 \% \\
12,28 \%\end{array}$ & $\begin{array}{c}192.156 \\
41,71 \% \\
29,43 \%\end{array}$ & $\begin{array}{c}\mathbf{4 6 0 . 7 5 0} \\
100,00 \% \\
70,57 \%\end{array}$ & $\begin{array}{c}652.906 \\
- \\
100,00 \%\end{array}$ \\
\hline San Juan & $\begin{array}{c}230.401 \\
75,74 \% \\
57,46 \% \\
\end{array}$ & $\begin{array}{c}19.239 \\
6,32 \% \\
4,80 \%\end{array}$ & $\begin{array}{l}\mathbf{5 4 . 5 4 6} \\
17,93 \% \\
13,60 \%\end{array}$ & $\begin{array}{l}73.785 \\
24,26 \% \\
18,40 \%\end{array}$ & $\begin{array}{l}96.765 \\
31,81 \% \\
24,13 \%\end{array}$ & $\begin{array}{c}\mathbf{3 0 4 . 1 8 5} \\
100,00 \% \\
75,87 \% \\
\end{array}$ & $\begin{array}{c}400.950 \\
- \\
100,00 \%\end{array}$ \\
\hline San Luis & $\begin{array}{c}\mathbf{1 7 1 . 7 8 4} \\
96,11 \% \\
71,41 \%\end{array}$ & $\begin{array}{l}4.004 \\
2,24 \% \\
1,66 \%\end{array}$ & $\begin{array}{l}2.955 \\
1,65 \% \\
1,23 \%\end{array}$ & $\begin{array}{l}\mathbf{6 . 9 5 8} \\
3,89 \% \\
2,89 \%\end{array}$ & $\begin{array}{l}\mathbf{6 1 . 8 0 4} \\
34,58 \% \\
25,69 \%\end{array}$ & $\begin{array}{c}\mathbf{1 7 8 . 7 4 2} \\
100,00 \% \\
74,31 \%\end{array}$ & $\begin{array}{c}240.545 \\
- \\
100,00 \%\end{array}$ \\
\hline Santa Cruz & $\begin{array}{c}84357 \\
89,82 \% \\
69,62 \% \\
\end{array}$ & $\begin{array}{c}3027,5 \\
3,22 \% \\
2,50 \%\end{array}$ & $\begin{array}{c}6528,5 \\
6,95 \% \\
5,39 \%\end{array}$ & $\begin{array}{c}\mathbf{9 . 5 5 6} \\
10,18 \% \\
7,89 \%\end{array}$ & $\begin{array}{l}27.249 \\
29,02 \% \\
22,49 \% \\
\end{array}$ & $\begin{array}{c}\mathbf{9 3 . 9 1 3} \\
100,00 \% \\
77,51 \% \\
\end{array}$ & $\begin{array}{c}121.162 \\
- \\
100,00 \%\end{array}$ \\
\hline Santiago del Estero & $\begin{array}{c}\mathbf{3 1 4 . 8 4 0} \\
93,27 \% \\
62,35 \% \\
\end{array}$ & $\begin{array}{c}11.081 \\
3,28 \% \\
2,19 \% \\
\end{array}$ & $\begin{array}{c}\mathbf{1 1 . 6 5 1} \\
3,45 \% \\
2,31 \% \\
\end{array}$ & $\begin{array}{c}22.732 \\
6,73 \% \\
4,50 \% \\
\end{array}$ & $\begin{array}{c}167.363 \\
49,58 \% \\
33,15 \% \\
\end{array}$ & $\begin{array}{c}\mathbf{3 3 7 . 5 7 1} \\
100,00 \% \\
66,85 \% \\
\end{array}$ & $\begin{array}{c}\mathbf{5 0 4 . 9 3 4} \\
- \\
100,00 \% \\
\end{array}$ \\
\hline Tucumán & $\begin{array}{c}494.599 \\
84,46 \% \\
58,27 \% \\
\end{array}$ & $\begin{array}{c}20.709 \\
3,54 \% \\
2,44 \% \\
\end{array}$ & $\begin{array}{c}\mathbf{7 0 . 2 6 9} \\
12,00 \% \\
8,28 \% \\
\end{array}$ & $\begin{array}{c}90.977 \\
15,54 \% \\
10,72 \% \\
\end{array}$ & $\begin{array}{c}\mathbf{2 6 3 . 2 1 4} \\
44,95 \% \\
31,01 \% \\
\end{array}$ & $\begin{array}{c}\mathbf{5 8 5 . 5 7 6} \\
100,00 \% \\
68,99 \% \\
\end{array}$ & $\begin{array}{c}848.790 \\
- \\
100,00 \% \\
\end{array}$ \\
\hline $\begin{array}{c}\text { Tierra del } \\
\text { Fuego }\end{array}$ & $\begin{array}{l}35.212 \\
72,85 \% \\
52,46 \% \\
\end{array}$ & $\begin{array}{l}\mathbf{3 . 4 2 1} \\
7,08 \% \\
5,10 \% \\
\end{array}$ & $\begin{array}{c}9.699 \\
20,07 \% \\
14,45 \% \\
\end{array}$ & $\begin{array}{l}13.120 \\
27,15 \% \\
19,55 \% \\
\end{array}$ & $\begin{array}{l}18.789 \\
38,88 \% \\
27,99 \% \\
\end{array}$ & $\begin{array}{c}\mathbf{4 8 . 3 3 1} \\
100,00 \% \\
72,01 \% \\
\end{array}$ & $\begin{array}{c}67.120 \\
- \\
100,00 \% \\
\end{array}$ \\
\hline
\end{tabular}

Nota: El primer renglón de cada categoría expresa el número absoluto de votos que la conforma, el segundo señala el lugar relativo con relación a la participación activa total (concurrencia), mientras que el tercer reglón lo hace con respecto al total de votantes habilitados (Padrón electoral). Fuente: Elaboración propia en base datos Ministerio del Interior.

De esta manera, creemos conveniente considerar la verdadera novedad e irrupción de las jornadas: la "aparición" del "voto bronca". En efecto, el 'voto bronca' (como fue titulado y publicitado por la mayoría de los medios de comunicación) se convirtió sin dudas en la característica más saliente del escrutinio de octubre. Como vemos en el Cuadro $\mathrm{N}^{\circ} 2$, ante la dificultad de ser medido con fidelidad, hemos optado por comprenderlo a través de la suma de los votos en blanco y nulos. Así, si repasamos brevemente lo ocurrido en las elecciones precedentes, aquí sí notamos la existencia de una ruptura notoria con respecto a años anteriores. La media histórica señala que el "voto bronca" representó tan sólo el 4,07\% de la participación

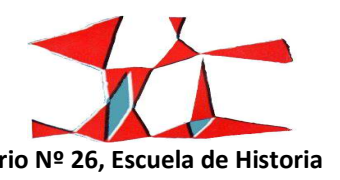

Facultad de Humanidades y Artes (Universidad Nacional de Rosario), 2014

pp. 282-304

ISSN 1853-8835 
efectiva, mientras que en el octubre de 2001 casi se sextuplicó, llegando a ser la opción de casi una cuarta parte del electorado (23,30\%).

Por supuesto, no todas las formas de protesta con el voto tienen la misma contundencia o sentido. Por ejemplo, la ausencia en el acto electoral puede indicar por su carácter silencioso cierta ambigüedad o indiferencia frente al sistema, la posibilidad de votar en blanco si bien señala un grado mayor de compromiso que abstenerse de participar (expresa el descontento de manera activa), implica también una modalidad mucho más suave y cívica de descontento que la anulación. En principio, existieron notorias diferencias porcentuales según los distritos electorales entre ambas opciones que nos indican que las personas que efectivamente concurrieron al escrutinio se inclinaron por uno u otro método según su intención de emitir distintos mensajes. En efecto, las profundas diferencias entre las circunscripciones así lo avalan. En sólo dos distritos (Capital Federal y Río Negro), los votos anulados cuadriplicaron a los votos en blanco. En Chubut, Entre Ríos, La Pampa, San Juan, Tucumán y Tierra del Fuego (seis distritos) la diferencia fue de 3 a 1. Siendo en Mendoza, Formosa, Neuquén y Santa Cruz una situación en la cual los primeros duplicaron a los segundos. Para las provincias de Santa Fe, La Rioja, Salta y Catamarca ocurrieron casos totalmente contrarios a los anteriores: los votos en blanco superaron a los anulados. El caso más notorio fue el ocurrido en la provincia de Santa Fe, donde se registró la mayor distancia (30,58\% frente a un 11,50\%). En cinco distritos no se observan diferencias notorias entre uno y otro fenómeno (Córdoba, Buenos Aires, Santiago del Estero, Misiones y Jujuy), en los cuales la expresión del descontento asumió ambas formas por igual. En Chaco y Santa Cruz, el enfado se expresó en una medida muy minoritaria, casi imperceptible, tomando valores por debajo de los 2 dígitos (7,17\% y 7,89\% respectivamente). Mientras que en San Luis y Corrientes prácticamente no se registraron formas de protestas contundentes del "voto bronca" (3,89\% y 2,65\% para cada caso).

A su vez, en ambos casos (ya sea votando en blanco o anulando) se emitía el mismo mensaje: los sufragantes (cerca de 4,5 millones de personas) podrían haber emitido un voto positivo apoyando a alguna lista pero prefirieron no hacerlo. En este sentido, la apertura del espacio simbólico de representaciones sociales se volvía sonora de una nueva forma. En las elecciones de 2001 no existió el clásico mecanismo electoral de un "voto castigo tradicional" contra el partido gobernante a través de apoyar a otro, en el cual el partido opositor cosechara una victoria a costa de un gobierno que fuera derrotado, como fue por ejemplo el caso de la UCR en 1987 gracias a las victorias del PJ o el mismo PJ luego, en 1997, a manos de la Alianza. Para

291

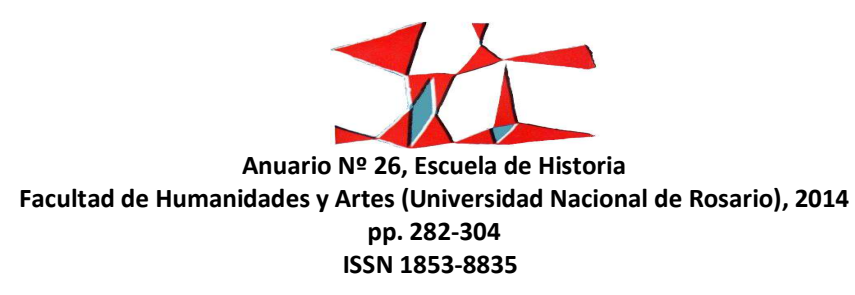


las elecciones de 2001 hubo, en cambio, una alta movilización electoral, si bien más baja con respecto a otros años, mayoritaria al fin, en la cual un importante segmento de la población participó en forma activa en el proceso y no vislumbró a ningún candidato que fuera capaz de representarla. La crítica, el enojo y la "bronca" mayoritarias fueron plasmadas bajo nuevas formas de cuestionamiento, refractando las coordenadas del espacio político. El descontento se tradujo de manera tal que complejizaban sus espacios de significación, haciendo difícil para cualquier candidato poder posicionarse de manera legítima a través del apoyo plebiscitario. Los principales partidos políticos habían resultado derrotados -o por lo menos muy cuestionados- en su conjunto y también en forma individual.

A su vez, el caso específico del voto anulado (mayoritario en los grandes centros urbanos) representó sin dudas otras implicancias, dado que este acto consiste en una forma de expresión más directa y clara: el votante sólo tiene que introducir en el sobre cualquier cosa menos una boleta electoral oficial. De este modo, los ciudadanos que se expresaron bajo este método pudieron señalar notoriamente la dirección de su intención de descontento o rechazo, ya que nadie podría interpretar desinterés, apatía o incapacidad para emitir el voto. Mucho menos de la manera en que la emisión se hizo. En la mayoría de los casos los gestos de anulación fueron bien claros y explícitos: boletas rotas, escrituras de insultos hacia los candidatos y demás intentos de llamar la atención a base de un repudio generalizado. Así se multiplicaron las formas de creatividad y originalidad. En algunos casos existieron boletas con una figura de la historia nacional (San Martín, Belgrano, Evita, etc.), denotando un supuesto contraste entre la mediocridad de "los políticos" del momento y los próceres. También hubo formas de plasmar el descontento a través del humor cínico: fueron introducidos en los sobres denunciando la corrupción de "los políticos" las fotos de un personaje de Alberto Olmedo (el dictador de Costapobre), dibujos de Clemente ("No tiene manos, a lo mejor no roba"), Afancio ("el político que menos roba"), Mafalda o "Ningún Partido" ("candidatos a seguir afanando una vez más en nombre del pueblo $\left.{ }^{7 \prime}\right)$. En otros, se apeló a introducir mensajes mucho más claros y agresivos: fetas de fiambres, preservativos, fotos de Osama Bin Laden, papel higiénico y hasta un polvo blanco que simulaba ser esporas del ántrax (reforzando la psicosis mundial sobre posibles ataques terroristas que dominaba la escena un mes después del ataque a las torres gemelas en Estados Unidos).

\footnotetext{
${ }^{7}$ Bonnet, Alberto. “Elecciones 2001: nadie vota a nadie”. Cuadernos del Sur, Año 17, N 32, Bs. As., 2001, p.29.
}

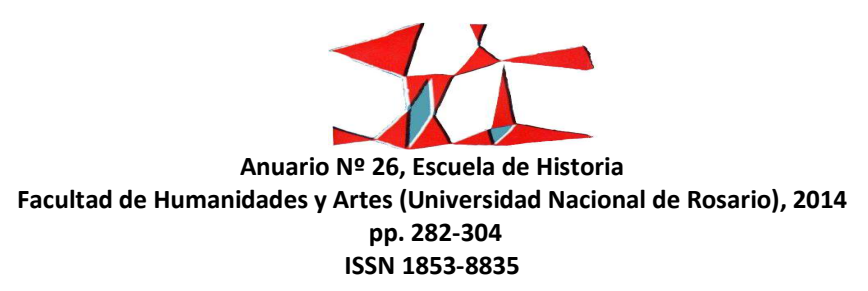




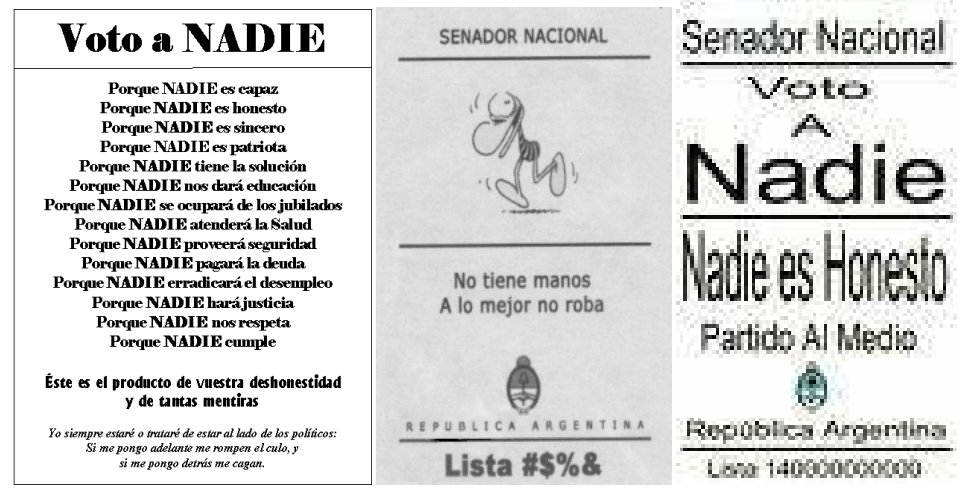

Algunas de las boletas que expresaban el "voto bronca"

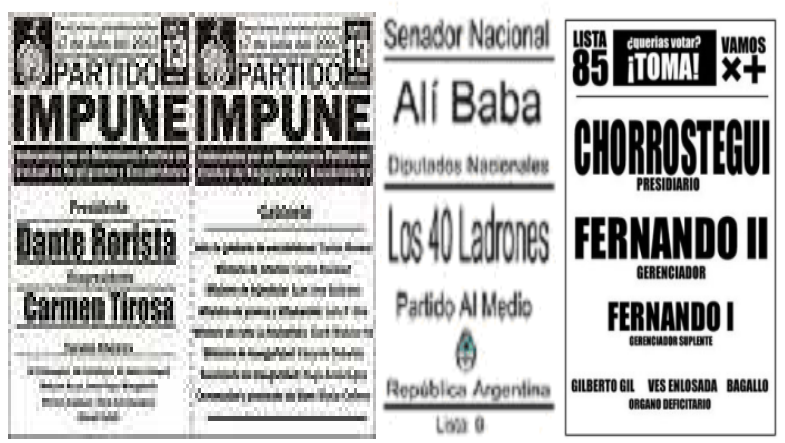

Las consecuencias del "voto bronca": sus resultados políticos y los problemas de su ambigüedad

Desgraciadamente una de las (tantas) deficiencias que posee el sistema electoral argentino es la carencia de mecanismos de traducción institucional para fenómenos como los ocurridos en octubre de 2001; ya que según las leyes electorales vigentes sólo se registran como votos válidos aquellos en los cuales existe una boleta oficial emitida. Es decir, votar en blanco o impugnar el voto sólo restan sufragios al universo total considerado para la distribución de los cargos electorales. Por más que en varios distritos se hayan impuesto las diversas formas de protesta -como el voto en blanco- todas las bancas parlamentarias -por ejemplodeben ser asignadas a personas físicas, no pudiendo quedar alguna sin titular. A su vez, tampoco se contemplan los casos en que el descontento logra "ganar" en los distritos electorales. Que el "voto bronca" haya triunfado no obligaba legalmente a las autoridades a convocar de forma automática a elecciones generales, haciendo caducar los cargos en vigencia y elegir nuevamente los puestos ejecutivos (como

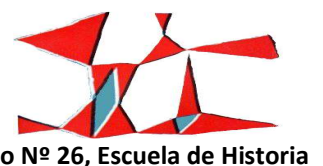

Facultad de Humanidades y Artes (Universidad Nacional de Rosario), 2014 pp. 282-304

ISSN 1853-8835 
Presidente de la Nación) o renovar totalmente los cargos legislativos ${ }^{8}$. De este modo, obtienen un mayor lugar institucional sólo aquellos que tuvieron votos positivos, siendo esto algo que -en una coyuntura como la del 2001- distorsionaba severamente la traducción de la participación efectiva. Veámoslo por partes.

En la Capital Federal donde la Alianza con la candidatura de Rodolfo Terragno se declaró "ganadora", obteniendo por la "mayoría" 2 de los 3 senadores en juego, lo hizo con el 20,5\% de los votos válidos (275.762 votos), quedando muy lejos de los 543.817 que obtuvo el 'voto bronca'. Así, su "triunfo" como "mayoría" representó tan sólo el 14,6\% del total de los participantes y apenas el 10,7\% del padrón electoral, y sin embargo se quedó con el $66 \%$ de las bancas del Senado. A su vez, afloraron en este distrito candidatos "castigo" (como Luis Zamora y Patricia Walsh) y se verificó una gran fuga de votos hacia los partidos considerados tradicionalmente de izquierda. Por parte del acuerdo registrado entre el partido de Cavallo (Acción por la República) y el Partido Justicialista (PJ), sólo se lograron obtener 2 puestos legislativos con 153.198 votos, algo muy lejano de los 528.250 votos que tuvieron sumados en 1999 y, todavía más, si consideramos los 667.286 sufragios obtenidos en 1997.

En la provincia de Bs. As., el distrito electoral más importante del país, se registraron también fenómenos del mismo tipo. El PJ con la lista encabezada por Eduardo Duhalde, que perdió las elecciones de 1999 cuando obtuvo 2.686 .853 votos, "ganó" en 2001 con cerca de 700 mil sufragios menos (2.026.669 votos), quedando el "voto bronca" en un número cercano, 1.747.785 sufragios. A su vez, la lista de la Alianza, encabezada por Raúl Alfosín, Storani y Moreau se alzó en "segundo lugar" con menos de la mitad de éstos votos castigos (822.050 sufragios). De esta manera, las 2 principales listas "triunfaron" obteniendo los 3 cargos para senadores ( 2 por la "mayoría" y 1 por la minoría: el 100\% de la representación senatorial) con el $28,32 \%$ y $11,49 \%$ del total de los participantes respectivamente, sumando entre ambos partidos "mayoritarios" tan sólo el $30 \%$ de los votos del padrón electoral.

Aunque, sin dudas, el lugar donde fue mayor la distorsión entre participación efectiva y aquella institucionalmente válida fue la provincia de Santa Fe. Aquí, el justicialismo se declaró "ganador" con el $35,30 \%$ de los votos positivos (348.517 sufragios), seguido por la Alianza que obtuvo el $25,82 \%$ de los mismos

\footnotetext{
${ }^{8}$ El caso de las elecciones de 2001 represente un caso especial, ya que como era la primera elección en la cual los Senadores nacionales fueron elegidos en forma directa por la ciudadanía -y no a través de las cámaras legislativas distritales- el Senado sería renovado en su totalidad. Nuestro señalamiento refiere a que el recambio parlamentario no fue causado por los resultados electorales, sino por una cuestión ajena al mismo.
}

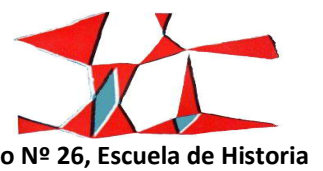

Facultad de Humanidades y Artes (Universidad Nacional de Rosario), 2014

pp. 282-304

ISSN 1853-8835 
(254.953 votos), valores muy por detrás -aún sumados- a los 717.340 que sacó el "voto bronca" (el 42,08\% del total de participantes, frente al $20,44 \%$ del PJ y $14,96 \%$ de la Alianza). El PJ que también había sido derrotado en Santa Fe en 1999, se declaró "triunfador" en 2001 habiendo perdido casi 200 mil sufragios y obteniendo menos de la mitad de los que obtuvo el "voto bronca". Por su parte, en la segunda provincia más grande del país, Córdoba, se repitió un proceso similar. El PJ "ganó" con el $26,9 \%$ de los votos validos (352.400), seguido muy de cerca por la Alianza que obtuvo el 25,5\% (334.388 votos), pero siendo derrotados (ambos) por el "voto bronca" que sacó 355.264.

Cuadro $N^{\circ}$ 3: Sufragios absolutos y relativos y de la elecciones nacionales de los años 1997, 1999 y 2001 para el PJ, la Alianza y el "voto bronca" en los principales distritos electorales

\begin{tabular}{|c|c|c|c|c|c|c|c|c|c|}
\hline & \multicolumn{3}{|l|}{ PJ } & \multicolumn{3}{|c|}{ Alianza } & \multicolumn{3}{|c|}{ "Voto Bronca" } \\
\hline & 1997 & 1999 & 2001 & 1997 & 1999 & 2001 & 1997 & 1999 & 2001 \\
\hline \multirow{4}{*}{$\begin{array}{l}\text { Capital } \\
\text { Federal }\end{array}$} & 339.073 & 609.447 & 153.198 & 1.090 .843 & 1.051 .578 & 275.762 & 85.560 & 78.078 & 543.817 \\
\hline & $26,88 \%$ & $30,92 \%$ & $11,40 \%$ & $56,80 \%$ & $53,36 \%$ & $20,52 \%$ & - & - & - \\
\hline & $20,38 \%$ & $29,64 \%$ & $8,11 \%$ & $54,41 \%$ & $51,14 \%$ & $14,61 \%$ & $4,16 \%$ & $4,69 \%$ & $28,81 \%$ \\
\hline & $16,49 \%$ & $24,05 \%$ & $5,93 \%$ & $42,90 \%$ & $41,50 \%$ & $10,67 \%$ & $3,38 \%$ & $3,80 \%$ & $21,03 \%$ \\
\hline \multirow{4}{*}{$\begin{array}{c}\text { Buenos } \\
\text { Aires }\end{array}$} & 2.846 .238 & 2.686 .853 & 2.026 .669 & 3.315 .703 & 3.104 .469 & 822.050 & 483.741 & 288.110 & 1.747 .785 \\
\hline & $41,44 \%$ & $37,26 \%$ & $37,48 \%$ & $48,28 \%$ & $43,05 \%$ & $15,20 \%$ & - & - & - \\
\hline & $38,24 \%$ & $34,91 \%$ & $28,32 \%$ & $44,54 \%$ & $40,34 \%$ & $11,49 \%$ & $6,29 \%$ & $3,87 \%$ & $24,42 \%$ \\
\hline & $32,79 \%$ & $29,26 \%$ & $21,83 \%$ & $38,19 \%$ & $33,80 \%$ & $8,85 \%$ & $5,27 \%$ & $3,32 \%$ & $18,82 \%$ \\
\hline \multirow{4}{*}{ Córdoba } & 437.446 & 204.648 & 352.400 & 538.961 & 773.765 & 334.388 & 76.627 & 171.275 & 355.264 \\
\hline & $30,93 \%$ & $12,26 \%$ & $26,90 \%$ & $38,11 \%$ & $46,36 \%$ & $25,52 \%$ & - & - & - \\
\hline & $27,59 \%$ & $11,72 \%$ & $21,26 \%$ & $33,99 \%$ & $44,32 \%$ & $20,17 \%$ & $4,39 \%$ & $10,80 \%$ & $21,43 \%$ \\
\hline & $21,38 \%$ & $9,67 \%$ & $16,17 \%$ & $26,34 \%$ & $36,54 \%$ & $15,34 \%$ & $3,62 \%$ & $8,37 \%$ & $16,30 \%$ \\
\hline \multirow{4}{*}{ Santa Fe } & 573.551 & 538.187 & 348.517 & 412.597 & 590.181 & 254.953 & 76.396 & 402.276 & 717.340 \\
\hline & $45,46 \%$ & $32,15 \%$ & $35,30 \%$ & $32,70 \%$ & $35,25 \%$ & $25,82 \%$ & - & - & - \\
\hline & $36,17 \%$ & $30,74 \%$ & $20,44 \%$ & $26,02 \%$ & $33,71 \%$ & $14,96 \%$ & $4,36 \%$ & $25,37 \%$ & $42,08 \%$ \\
\hline & $28,03 \%$ & $25,16 \%$ & $15,85 \%$ & $20,17 \%$ & $27,60 \%$ & $11,59 \%$ & $3,57 \%$ & $19,66 \%$ & $32,62 \%$ \\
\hline
\end{tabular}

Nota: El primer renglón de cada categoría índica el número absoluto de votos, el segundo señala el lugar relativo con relación a los votos positivos, el tercero con la participación activa total, mientras que el cuarto renglón lo hace con respecto al total de votantes habilitados. En todos los casos, de cada distrito. Fuente: Elaboración propia en base datos Ministerio del Interior ${ }^{9}$.

Por lo cual, tomando los cuatro principales distritos electorales del país (que forman el 65\% del padrón electoral nacional) el "voto bronca" fue el que registró la mejor performance frente al PJ y la Alianza, dato que no es de ninguna manera menor, ya que los más importantes líderes políticos con ese resultado vieron menguar su principal capital simbólico (los votos), lo que afectaba severamente sus posiciones en el terreno

\footnotetext{
${ }^{9}$ Aclaración metodológica: los datos para la elección de 1997 representan los votos para diputados nacionales de cada provincia. Los de 1999 son el promedio obtenido entre los votos para presidente de la nación y diputados nacionales. Para el caso de 2001 se tomó el promedio entre los sufragios para senadores y diputados de la nación.
}

295

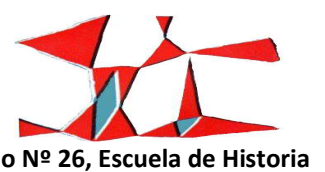

Facultad de Humanidades y Artes (Universidad Nacional de Rosario), 2014

pp. 282-304

ISSN 1853-8835 
de juego. De allí en adelante todos disminuyeron su legitimidad ante el grueso de la población al ver mancillada su principal fuente de respaldo. Así, los dirigentes políticos con mayor relevancia fueron muy duramente cuestionados en sus propios distritos. Carlos Reuteman y Juan Manuel de la Sota debieron comenzar a revaluar sus aspiraciones presidenciales tras los números recibidos en las urnas, el "voto bronca" había logrado ser vencedor en sus distritos. El binomio bonaerense Ruckauf-Duhalde, si bien pudo salvar sus ropas, lo hizo a duras penas perdiendo un $25 \%$ de los sufragios que obtuvo dos años antes, momento en que fue derrotado. Los principales candidatos aliancistas que buscaron convertirse en uno polo alternativo de poder al interior de la coalición de gobierno, también sufrieron estrepitosas derrotas en manos del descontento ciudadano. Alfonsín, Terragno, Ibarra, Moreau y Storani (de las listas "oficialistas", pero opositoras al gobierno) fueron superados en todos los casos por el "voto bronca", quien los duplicó en sus sufragios. Por lo cual, podemos sacar una primera conclusión de relevancia: los partidos tradicionales (el PJ y de la coalición aliancista UCR-Frepaso) vieron disminuir su caudal electoral de una manera arrolladora frente al descontento mayoritario. Esto era algo que los perjudicaba duramente en cualquier aspiración que tuviesen para el futuro inmediato. Sus planes no podrían llevarse a cabo con facilidad con los números recibidos.

A su vez, también debemos decir que los "nuevos partidos", que gustaban definirse como parte de la "nueva política", no lograron obtener de ninguna manera los resultados esperados. Por ejemplo, tanto la Afirmación para una República Igualitaria (ARI) de Elisa Carrió como el Polo Social del Padre Farinello se habían entusiasmado con obtener un segundo lugar en la provincia de Buenos Aires, distrito donde no alcanzaron a llegar a los dos dígitos de los votos válidos (9,11\% y 8,64\% respectivamente). Ambas performances (492.688 y 467.016 votos para cada caso), no fueron más que la cuarta parte de la que tuvo el "voto bronca". En Capital Federal, donde el ARI pensó tener asegurado un primer lugar durante mucho tiempo (proyectando una victoria por encima del $40 \%$ de los votos), finalmente salió tercero con 168.851 sufragios (12,6\% de los votos válidos), representando menos de la tercera parte del voto bronca. Mientras que el Polo Social, que había implementado una política de alianza con todos los sectores posibles, terminó octavo con el 2,5\% de los votos validos y el $0,02 \%$ de participación efectiva (32.926 sufragios).

Ahora bien, cabría preguntarse si a partir de los datos de las jornadas de octubre hubo algún ganador efectivo. En principio, los números registrados se encuentran plagados de contrasentidos y ambigüedades, que pueden señalar direcciones muchas veces paradójicas, cuando no, francamente contradictorias. Aunque

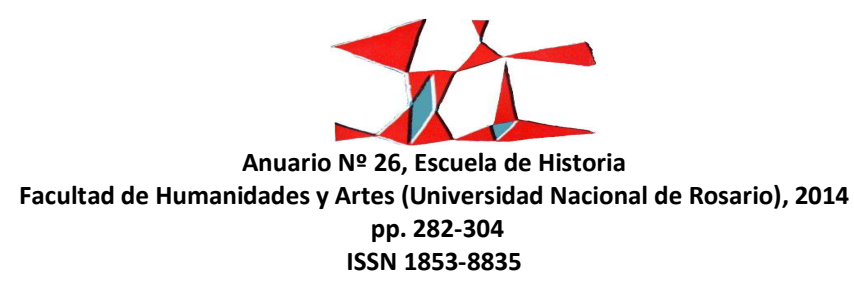


sin dudas, creemos que el más importante triunfo fue el que logró gran parte de la ciudadanía al crear nuevas formas para expresar sus opiniones por fuera de los canales tradicionales: el claro mensaje de descontento plasmado en las urnas obligó a todos los actores en juego a tomar nota de lo ocurrido. No hacerlo era acabar con la frágil supervivencia que los atosigaba, algo que finalmente le terminó de ocurrir a De la Rúa dos meses después. Así, al haber respondido de manera mayoritaria a la pregunta electoral con formas diferentes a las esperadas ("voto bronca", excusación masiva de las autoridades de mesa, negarse a financiar a los partidos políticos a través de no emitir votos positivos ${ }^{10}$, etc.) señalaba otro tipo de intervención para el proceso en curso, siendo éste políticamente válido y -sobre todo- muy sonoro ${ }^{11}$. Aunque, en este sentido, guardaba ciertas aristas de dificultad para su comprensión. Por ejemplo, haber votado en blanco durante los años de la proscripción peronista, lejos de ser un voto "a-partidario", "sin sentido" o de rechazo a "Ios políticos", tenía una dirección bastante contundente: el apoyo hacia el peronismo. Sin embargo, en el caso de las elecciones de octubre de 2001, su dirección guardaba ciertas ambigüedades a resolver. Si bien el "voto bronca" y el descontento ciudadano hería a toda la clase política en general, no lo hacía en el mismo sentido y a todos por igual. Los resultados del escrutinio también les habían otorgado a varias de las figuras implicadas argumentos a su favor para maquillar su delicada situación. Octubre, más que una "derrota" para algunos, podría leerse como un "triunfo" para otros.

Así, luego de conocerse los resultados finales, el mismo domingo 14 de octubre, Elisa Carrió en una conferencia de prensa se declaró "satisfecha" y "contenta" por haber obtenido un tercer puesto a nivel nacional frente a un partido centenario (la UCR) y otro con más de medio siglo de vida (el PJ). Para ella, el ARI era tan sólo "un movimiento construido en menos de un año" que había logrado -sin embargo- duplicar el número de sus bancas legislativas en el Congreso Nacional ${ }^{12}$. Terragno (UCR) e Ibarra (Frepaso), a pesar de haber obtenido un triunfo más que objetable, habían logrado ser la lista más votada en la importante Capital Federal, lo que les daba las fuerzas suficientes como para disputar la conducción de sus respectivos partidos, así como "regenerar" a la "Alianza original" a través de apelar a reunificar el espacio progresista. Decía Terragno tras su victoria: “Así como la Alianza surgió de aquí y se extendió por todo el país por la capacidad

\footnotetext{
10 Uno de los motivos de quienes emitieron el "voto bronca" fue impedir que el Estado Nacional destinara recursos a los diversos partidos políticos por cada voto obtenido. De este modo, la intención presente en muchos fue no votar afirmativamente para no financiar a "los políticos".

${ }^{11}$ Como se ha señalado: "Puede pensarse entonces que para una porción alta del electorado el voto es eficaz para expresar un repudio, más que para escoger a un representante [...] El ausentismo sugiere, en principio, repudio al sistema electoral, descreimiento en su eficacia. El 'voto bronca' sugiere en cambio aceptación del sistema electoral, reconocimiento de un mínimo de eficacia: si no para escoger, sí para denunciar". Vilas, Carlos. "Con bronca y como junando...Las elecciones del 14 de octubre 2001". Realidad Económica, N 183, 2001, p. 133.
}

12 Clarín (15/10/2001)

297

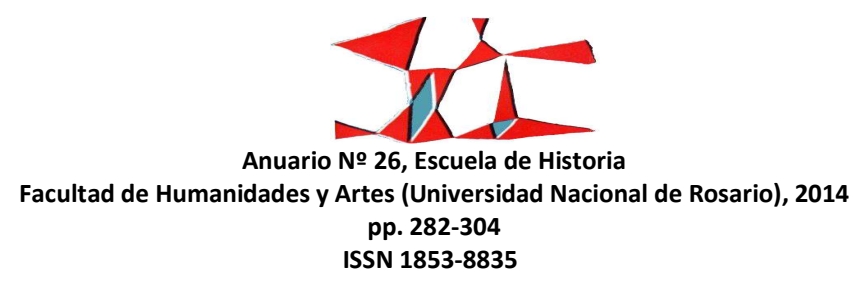


de amplificación que tiene la Capital Federal, ahora estamos en condiciones de hacer un esfuerzo de reunificación de las fuerzas progresistas" ${ }^{13}$. Con lo que empezaron a tejerse contactos fluidos entre éstos y Elisa Carrió, luego de declarar Aníbal Ibarra que no tenía "diferencias de fondo" con la líder del ARI ${ }^{14}$. Una nueva "Alianza" con proyecciones nacionales y con la intención de condicionar al gobierno, dado que salía de su propio riñón, apostó a resurgir de la mano de estas tres figuras. Por otra parte, el malogrado desempeño de Alfonsín, Moreau y Storani en la provincia de Buenos Aires que generó una pérdida de más de 2 millones de votos con relación al año 1999 y 2,5 millones con respecto a 1997, no fue letal. Con los números obtenidos, fue suficiente como para ser la lista aliancista más votada de todo el país, obteniendo un cómodo segundo lugar que duplicaba en votos a los partidos que decían representar "la nueva política" y que le alcanzó para convertir a Alfonsín en senador nacional por parte de la Alianza. Así, Alfonsín se creyó con el suficiente aire político para señalar que, según su criterio y "el de los más importantes dirigentes de la UCR", la población había votado contra Cavallo, señalando (en un acto realizado en la CGT) que éste "ya había cumplido su ciclo"15.

Aunque sin dudas, si de exhibir resultados electorales halagadores y con traducción institucional se trata, fue el PJ el que quedó mejor posicionado de todos. La derivación directa del escrutinio de octubre convirtió al peronismo en el claro triunfador de las jornadas: fue la lista más votada en 18 de los 24 distritos electorales (incluyendo los 3 más grandes), retuvo su mayoría en la Cámara de Senadores y se convirtió en la primera fuerza en la Cámara de Diputados desplazando a la Alianza. De este modo, podría ser verdad que el PJ se declarara "ganador" habiendo retrocedido en más de un millón de votos con respecto a la anterior elección legislativa (1997) y más de dos millones en relación a 1999, años en los cuales "perdió", pero lo cierto era que -de ahora en más- el Congreso Nacional y la mayoría de las legislaturas provinciales quedarían a merced de los dictados del Justicialismo, lo que posibilitaba que el PJ pudiese controlar los principales recursos institucionales del país. Además, convertido en la primera fuerza legislativa en Diputados y Senadores nacionales, la presidencia de ambas Cámaras legislativas se le volvía una presa fácil de alcanzar. El peronismo, oliendo la posibilidad cierta de poder volver al gobierno, podría no sólo atosigar al gobierno nacional con su crecido poder institucional, sino que también sería capaz de imponer con su sola fuerza la

${ }^{13}$ Citado en Bonnet, Alberto. “Elecciones 2001: nadie vota a nadie”. Cuadernos del Sur, Año 17, N 32, Bs. As., 2001 , p. 26.

${ }^{14}$ Clarín (17/10/2001).

${ }^{15}$ Clarín (19/10/2001).

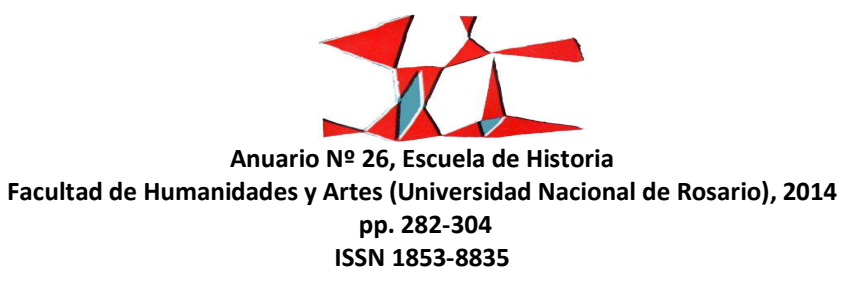


línea sucesoria detrás de la figura de De la Rúa, poniendo a los presidentes de las Cámara de Senadores y de Diputados. Es decir, si éste no pudiese terminar su mandato (como de hecho sucedió), el justicialismo ya estaba listo para sucederlo. Después de todo, los principales líderes partidarios no habían hecho tan mala elección: Reuteman y De la Sota habían logrado que sus listas se impusieran en sus provincias, la boleta que llevaba a Menem como candidato en La Rioja ganó con el $56 \%$ de los sufragios válidos (47\% de la participación efectiva), siendo Eduardo Duhalde el candidato más votado de todo el país.

\section{El único resultado certero: la derrota de la Alianza}

Dados los resultados de las elecciones de 2001, cabe preguntarse de dónde provinieron los casi 4,5 millones de adherentes del "voto bronca" y quién fue su destinatario inmediato, intentando captar cuál fue su intención manifiesta. Así, si consideramos que entre las elecciones legislativas de 2001 y las de 1997 la Alianza perdió más de 4,5 millones de votos, parece claro que el "voto bronca", lejos de ser indeterminado es un voto bastante preciso: si de bronca se trató, fue bronca contra el gobierno de la Alianza ${ }^{16}$, por lo que el irremediable derrotado de las elecciones fue el propio gobierno. Con respecto a su año triunfal, 1999, gracias al cual había logrado escalar hasta la presidencia de la nación, tan sólo había podido retener la tercera parte de esos sufragios, ien el camino había dilapidado 6 millones de votos! El partido de Domingo Cavallo, Acción por la República, retrocedió a menos de la mitad de los votos obtenidos en las elecciones legislativas de1997. A su vez, mientras que en 1999 se había jactado de casi duplicar el histórico millón de votos que tuvo Álvaro Alzogaray con la liberal UCeDé en 1989, en 2001 perdió el 85\% de sus votantes en todo el país. Así, la fuga de votos de la coalición gobernante resultó aplastante. Acción por la República, que en 1999 había contribuido decisivamente en la provincia de Buenos Aires para que Ruckauf obtuviera la gobernación, para el año 2001 prácticamente desapareció como fuerza electoral competitiva: apenas tuvo el $1 \%$ de los votos positivos. Cavallo, desmitificado como mago de la economía, salió de las elecciones de octubre tremendamente vapuleado por la ciudadanía ${ }^{17}$. Así, el 'voto bronca' se volvió la segunda preferencia a nivel nacional, a una distancia no muy lejana -apenas el 2,48\% del padrón electoral- de la primera (que fue el PJ), y superando en más de un millón de votos al Gobierno.

${ }^{16}$ Vilas, Carlos. “Con bronca y como junando...Las elecciones del 14 de octubre 2001”. Realidad Económica, N 183, Bs. As., 2001, p. 135.
${ }^{17} \mathrm{lb}$.

299

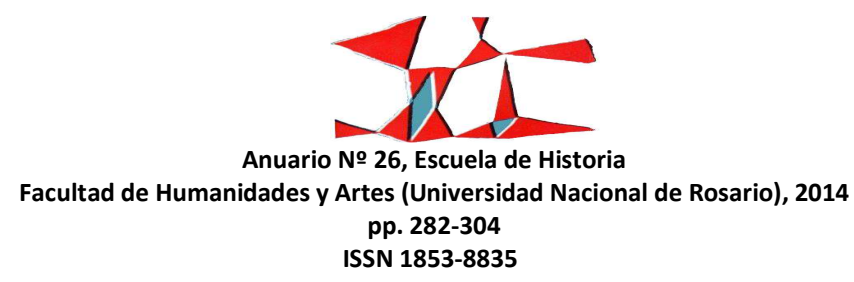




\section{Cuadro 4: Resultados absolutos y relativos de las elecciones de 1997, 1999 y 2001 a nivel nacional (total)}

\begin{tabular}{|c|c|c|c|}
\hline & $\mathbf{1 9 9 7}$ & $\mathbf{1 9 9 9}$ & $\mathbf{2 0 0 1}$ \\
\hline \multirow{3}{*}{ Alianza } & $\mathbf{7 . 8 5 4 . 8 3 0}$ & $\mathbf{9 . 1 6 7 . 4 0 4}$ & $\mathbf{3 . 2 0 5 . 7 0 1}$ \\
& $45,53 \%$ & $48,37 \%$ & $22,23 \%$ \\
& $42,52 \%$ & $46,19 \%$ & $17,05 \%$ \\
& $33,86 \%$ & $38,02 \%$ & $12,87 \%$ \\
\hline \multirow{3}{*}{ Partido Justicialista } & $\mathbf{6 . 2 6 7 . 9 7 3}$ & $\mathbf{7 . 2 5 4 . 1 4 7}$ & $\mathbf{4 . 9 8 8 . 4 0 7}$ \\
& $36,33 \%$ & $38,27 \%$ & $34,59 \%$ \\
& $33,93 \%$ & $36,55 \%$ & $26,54 \%$ \\
Acción por la República & $27,02 \%$ & $30,09 \%$ & $20,03 \%$ \\
\hline & $\mathbf{6 6 2 . 4 0 3}$ & $\mathbf{1 . 9 3 7 . 5 6 5}$ & $\mathbf{2 9 1 . 4 6 1}$ \\
& $3,84 \%$ & $10,22 \%$ & $2,02 \%$ \\
& $3,59 \%$ & $9,76 \%$ & $1.55 \%$ \\
& $2,86 \%$ & $8,04 \%$ & $\mathbf{1 , 7 7 \%}$ \\
\hline “Voto bronca” & $\mathbf{1 . 2 2 0 . 8 8 9}$ & $\mathbf{8 9 5 . 5 3 1}$ & $\mathbf{4 . 3 8 0 . 5 9 3}$ \\
& - & - & $23,30 \%$ \\
& $6,61 \%$ & $4,51 \%$ & $17,59 \%$ \\
\hline Votos Positivos & $5,26 \%$ & $3,71 \%$ & 14.420 .387 \\
\hline Participación Efectiva & 17.251 .484 & 18.953 .456 & 18.798 .991 \\
\hline Padrón Electoral & 23.1972 .735 & 19.848 .987 & 24.907 .838 \\
\hline
\end{tabular}

Nota: El primer reglón de cada categoría índica el número absoluto de votos, el segundo señala el lugar relativo con relación a los votos positivos, el tercero con la participación activa total, mientras que el cuarto reglón lo hace con respecto al total de votantes habilitados (Padrón electoral). Fuente: Elaboración propia en base datos Ministerio del Interior ${ }^{18}$.

La repercusión en la prensa extranjera al día siguiente de los comicios fue categórica: "Visible rechazo para el Presidente" (New York Times, EE. UU), "Derrota del Gobierno" (O Estado de Sao Paulo, Brasil)"19, "El peronismo derrota al Gobierno en las elecciones argentinas" (El País, España), "Quebranto de la Argentina" (Financial Times, Inglaterra). Una imagen presidencial en niveles terriblemente bajos (cuando no, expresamente negativos), asociaba la figura del presidente con la ineptitud, y con el estado de la economía al borde del colapso total, creando pobreza y miseria a todos sus costados, acompañado de un desempleo que no dejaba de crecer y que no hallaba su techo. Una fuerte degradación institucional, un gobierno asociado

${ }^{18}$ Aclaración metodológica: para la elección de 1997 bajo la categoría Alianza, fueron sumados también los votos de la UCR y el Frepaso para los casos en que fueron por separado. Para las de 1999 se procedió a tomar como muestra nacional los datos aportados sólo por la elección presidencial. En el caso del escrutinio de 2001, el PJ y Acción por la República conformaron una alianza electoral en algunos distritos -como la Capital Federal, Formosa, etc.-, ante la dificultad de desagregar los datos en forma fidedigna tal cual está conformado nuestro cuadro, nos hemos visto obligados comprendiendo que no es del todo legitimo hacerlo- a otorgar a cada una de las partes la mitad de los votos obtenidos en cada lugar en donde haya existido una alianza.

${ }^{19}$ Bonnet, Alberto. "Elecciones 2001: nadie vota a nadie". Cuadernos del Sur, Año 17, N 32, Bs. As., 2001, p. 39 , n.4.

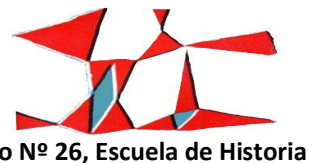

Facultad de Humanidades y Artes (Universidad Nacional de Rosario), 2014

pp. 282-304

ISSN 1853-8835 
a las peores prácticas corruptas (las cuales se había comprometido a pulverizar y parecían agravadas) junto con un horizonte futuro calamitoso, fueron algunos de los elementos que nos permiten entender el fracaso estrepitoso de las elecciones del 14 de octubre para el gobierno. Las fuerzas que habían conformado la Alianza lentamente habían ido desangrándose a lo largo del tiempo en que estuvieron a cargo del ejecutivo nacional. La deserción de Elisa Carrió, Chacho Álvarez, la CTA o Alicia Castro (sumados a un sinfín de legisladores), como el paso de cada uno ellos a las filas de la oposición, así lo indicaba. Los sectores que todavía no habían roto con el Gobierno quedaron muy cerca de hacerlo: el Frepaso estaba a punto de abandonar el barco que se hundía tras un inminente nuevo recorte presupuestario en el único ministerio que aún conservaba; la vieja estructura radical ya no podía soportar nuevas podas fiscales en sus distritos. Continuar así hubiera hecho que los gobernadores radicales se despidieran definitivamente de la idea de retener las gobernaciones que todavía no habían perdido a manos del peronismo. Los principales líderes partidarios de la UCR -y que pudieron festejar algún resultado en los comicios- estaban listos para recrudecer su discurso electoral combativo contra De la Rúa. Para ellos, en el Gobierno debían introducirse cambios de fondo (como el fin de la gestión de Cavallo) para evitar una lucha total. Si no se interpretaba lo ocurrido en los comicios como la posibilidad de realizar una claudicación absoluta y unilateral, el gobierno tenía que estar preparado para asumir su total soledad política; no sólo la que podrían propiciarle los hombres de su propio partido o aquellos que todavía formalmente lo acompañaban, sino también la que el PJ podría otorgarle, considerando que con la aplastante derrota sufrida en las urnas por parte del gobierno, el justicialismo se había adueñado de la llave del Congreso Nacional y de los principales resortes legislativos. Sin contar con el mensaje mayoritario de la población, para la cual la política económica debía modificarse forzosamente.

De este modo, con las elecciones de octubre, el proceso de la crisis 2001 terminó por construir una situación ya insostenible para el gobierno hacia adelante, dado que la brutal derrota electoral lo despojaba de uno de sus pilares de legitimidad más importantes. Su apelación plebiscitaria expresada en el apoyo popular se había desmoronado de manera notable. Así, tras el desbarranco económico final de la convertibilidad y la pérdida de su legitimidad fundamental evaporada (los votos), el gobierno de la Alianza terminó por quedar en franca caída libre y sin sostenes capaces (o siquiera interesados) en respaldarlo, creando todas las condiciones de un clima explosivo que lo empujó hacia su derrumbe final.

301

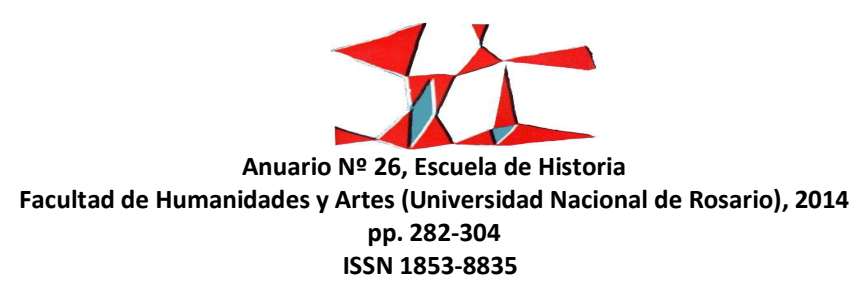




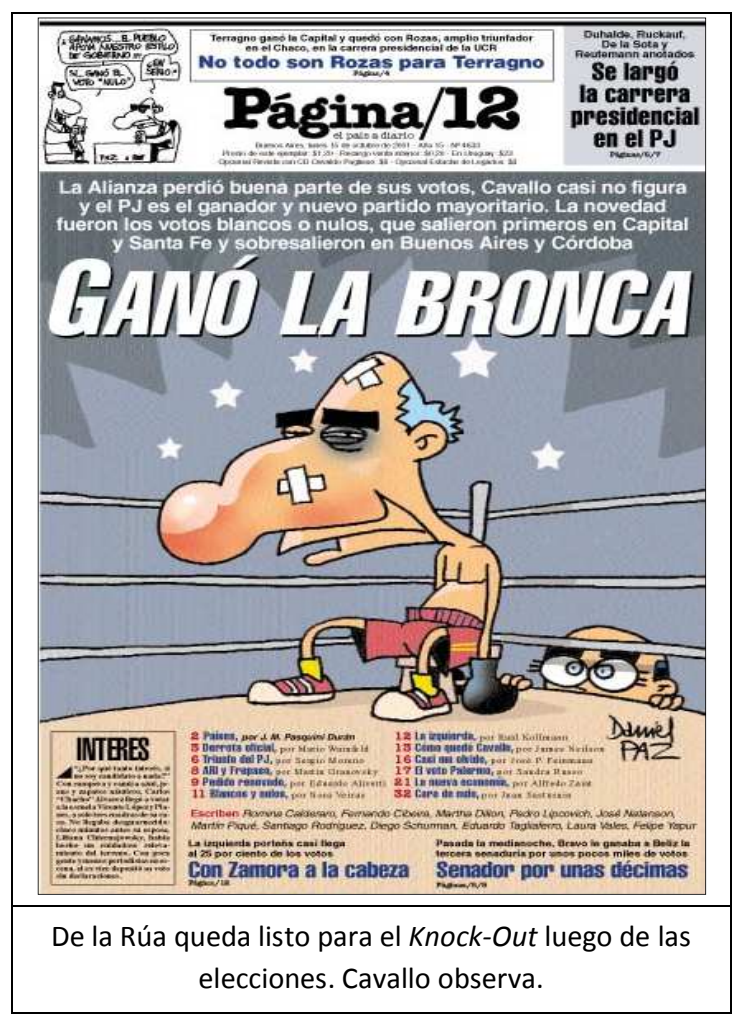

\section{Conclusión: El “voto bronca”, la caída de la Alianza y la legitimidad del orden político}

A lo largo de este trabajo hemos intentado abordar los resultados y formas de expresión de las elecciones legislativas nacionales del año 2001, donde vimos la importancia que registraron los hechos repasados a la hora de trasmitir un mensaje de fastidio y protesta frente al orden vigente, volviéndose el preludio que sentenció el final de la Alianza. En este sentido, la decadencia final del régimen de convertibilidad y la recesión económica que día a día pauperizaba la situación de millones de personas, conjugadas con la falta de respuestas políticas adecuadas por parte del gobierno de la Alianza transformó el tramo final del año 2001 de una crisis de acumulación del sistema (principalmente económica) a una crisis orgánica (principalmente política) afectando las formas de representación y el orden de la matriz societal, logrando así acelerar la descomposición de varias de las pautas políticas vigentes hasta entonces ${ }^{20}$. Esto permite explicar

\footnotetext{
20 Para una ampliación de esto ver nuestro trabajo Zícari, Julián. “Diciembre de 2001 en la Argentina. Movilización, saqueos y protesta popular". III Jornadas Internacionales de Problemas Latinoamericanos. Facultad de Ciencias Políticas y Sociales - Universidad Nacional de Cuyo, Mendoza, Noviembre de 2012.
}

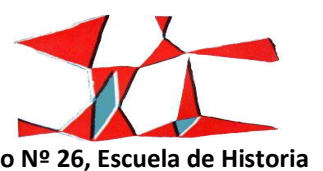

Facultad de Humanidades y Artes (Universidad Nacional de Rosario), 2014

$$
\text { pp. 282-304 }
$$

ISSN 1853-8835 
con vistas al futuro inmediato de ésas elecciones cómo y por qué el grito generalizado de "que se vayan todos" se expandió con tanta fuerza, como a su vez los levantamientos populares registrados durante diciembre de 2001 y el ciclo de protestas que de allí emergió, extremando hasta niveles inéditos los grados de conflictividad social. Por otra parte, los resultados electorales repasados también son un poderoso elemento explicativo para entender la dificultad de replantear un nuevo orden político una vez caído el gobierno de la Alianza (expresado en la existencia de cinco presidentes en apenas 10 días) ${ }^{21}$, como a su vez la debilidad con la que debieron surcar sus gobiernos Eduardo Duhalde (2002-2003) y parte de su presidencia Néstor Kirchner (20032007). Si el terreno de las elecciones es el espacio de la legitimación institucional, siendo uno de los campos primordiales para la constitución del orden social, es evidente que con los resultados obtenidos, todo el campo de las legitimidades se vio trastocado. El grueso de la población había participado, validando los mecanismos institucionales de representación, pero castigando en su conjunto a la corporación política, quedando ésta -y sobre todo el Gobierno- fuertemente golpeados. Así, se realizó un verdadero cuestionamiento político, de fondo, a partir de un uso original del voto y la democracia, donde el impulso de los votantes permitió repreguntarse -a la manera rousseauniana- por la legitimidad del "contrato social" (el por qué del orden social vigente), abriendo a partir de allí cambios importantes en la política argentina.

\section{Bibliografía}

Basset, Yann. "Abstención y voto negativo. De la interpretación sociológica a la lógica política" en Cheresky, Isidoro y Blanquer, Jean (comp.) De la ilusión reformista al descontento ciudadano. Las elecciones en la Argentina. 1999-2001. Homo Sapiens Ediciones, Rosario, 2001

Bonnet, Alberto. "Elecciones 2001: nadie vota a nadie". Cuadernos del Sur, Año 17, № 32, Bs. As., 2001

Herrero, Fabián; “«¿Pasividad desesperada o protesta astuta? ¿Desperdicio o mensaje a la clase política?» Intervenciones sobre cómo pensar el «voto bronca» en el momento previo a las elecciones nacionales de 2001", en Revista Estudios, Córdoba, N²6, 2011.

\footnotetext{
${ }^{21}$ Esto lo hemos trabajado en Zícari, Julián. "Gobernar con una sonrisa. La semana de Rodríguez Saá como presidente de la Nación". Realidad
} Económica, N2 272, Bs. As., 2012.

303

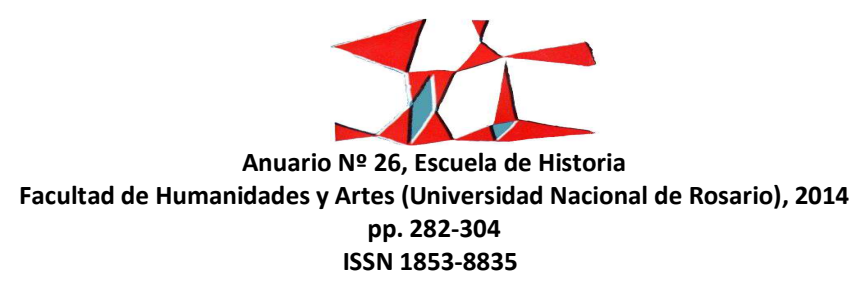


Vilas, Carlos. "Con bronca y como junando...Las elecciones del 14 de octubre 2001". Realidad Económica, № 183, 2001

Zícari, Julián. "Diciembre de 2001 en la Argentina. Movilización, saqueos y protesta popular". III Jornadas Internacionales de Problemas Latinoamericanos. Facultad de Ciencias Políticas y Sociales - Universidad Nacional de Cuyo, Mendoza, Noviembre de 2012.

Zícari, Julián. "El réquiem del uno a uno. Tres corridas bancarias y la instauración del corralito en el final de la convertibilidad". Realidad Económica, N²81, 1 de enero al 15 de febrero de 2014

Zícari, Julián. "Gobernar con una sonrisa. La semana de Rodríguez Saá como presidente de la Nación". Realidad Económica, № 272, Bs. As., 2012.

Recibido: 26 de septiembre de 2013

Aprobado: 28 de febrero de 2014

Versión final: 02 de junio de 2015 